\title{
Commentary: Inching way on the impervious path from art to science
}

\author{
Ivancarmine Gambardella, MD, FRCS, and Mario F. L. Gaudino, MD, FEBCTS
}

\author{
From the Department of Cardiothoracic Surgery, Weill Cornell Medicine, New York, NY \\ Disclosures: Authors have nothing to disclose with regard to commercial support. \\ Received for publication Aug 27, 2019; accepted for publication Aug 27, 2019; available ahead of print Oct 6, \\ 2019. \\ Address for reprints: Mario F. L. Gaudino, MD, FEBCTS, Department of Cardiothoracic Surgery, Weill Cornell \\ Medicine, 525 E 68th St, New York, NY 10065 (E-mail: mfg9004@med.cornell.edu). \\ J Thorac Cardiovasc Surg 2020;159:e189-90 \\ 0022-5223/\$36.00 \\ Copyright (C) 2019 by The American Association for Thoracic Surgery \\ https://doi.org/10.1016/j.jtcvs.2019.08.048
}

Valve repair is the established criterion standard for the surgical treatment of primary mitral regurgitation, as reflected in longtime official recommendations of professional society guidelines. ${ }^{1}$ The primacy of repair relative to replacement has been consolidated by a robust body of literature, which has in recent years been enriched by multi-institutional evidence spanning from operative to long-term results. For instance, the Mitral Regurgitation International Database analyzed a supranational sample from tertiary centers: after propensity-score matching, repair offered a lower operative mortality $(0.2 \%$ vs $4.4 \%$; $P<.01)$ and a higher 20 -year survival $(41 \%$ vs $24 \%$; $P<.01){ }^{2}$ Nonetheless, the latter evidence from tertiary centers cannot be translated to a broader surgical panorama that also encompasses centers without a niche for mitral valve surgery. For instance, a "real-world" sample was provided by an insightful analysis of mitral surgery patterns and results in New York State in the course of a decade (2002-2013; 5475 patients). ${ }^{3}$ The consequences of the wide variability in surgeons' annual volumes with regard to mitral operations (median, 10; range, 1-230) were proved to be clear. Surgeons without a special interest in mitral pathology ( $<10$ procedures/y) had a mean repair rate of $48 \%$, which paled in contrast to the $77 \%$ rate of mitral specialists ( $>50$ procedures/year). Experience had already paid off at the 1-year mark after repair: reoperation rates were $1.3 \%$ and $3.6 \%$, respectively, for surgeons with at least 25 repairs/y and those with fewer than 25 repairs/year $(P<.01)$. Most importantly, whereas repair was overall associated with a better survival than replacement (adjusted hazard ratio, $0.80 ; P<.01)$, total annual surgeon volume was an independent predictor of mortality for patients who underwent repair (adjusted hazard ratio, 0.96, $P<.01){ }^{3}$ It is thus of paramount importance to strive for a reliable assessment of the repair quality. Repair quality is ultimately ensured by an adequate juxtaposition of the cusps, which in turn is the product of equipoise between coapting and tethering forces. ${ }^{4}$ Intraoperatively, surgeons can avail themselves only of subjective methods to assess

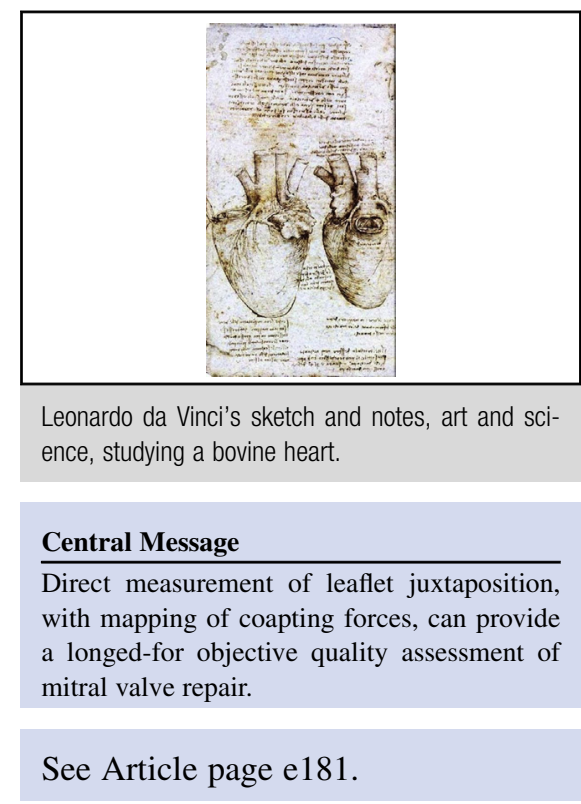

their handwork (eg, saline solution test, ink test), the intrinsic limit being their nonquantitative nature. ${ }^{5}$ The customary parameters provided by sonography are quantitative, yet they in fact are only an indirect measurement of the coaptation momentum ${ }^{6}$ and are provenly unable to predict future failure. ${ }^{7}$ In this issue of The Journal of Thoracic and Cardiovascular Surgery, Grinberg and colleagues ${ }^{8}$ propose a technology that aims at providing the longed-for direct and objective measurement of mitral coaptation. The principal weakness of their proposal is pardonable as being intrinsic to the early stage of such developing technology, that it was only tested in three ex vivo porcine heart models. Its redeeming value is that it is a step toward developing a method, to directly assess the parameter of interest (ie coaptation) in a quantitative and reproducible fashion. Professionally, what distinctively distinguishes art from science is that the latter has a method. Through a protocol, the scientific method looks at the reproducibility of measurable observations. The preliminary work of Grinberg and colleagues ${ }^{8}$ can be viewed as another step, inching away on the impervious path from art to science.

\section{References}

1. Nishimura RA, Otto CM, Bonow RO, Carabello BA, Erwin JP III, Fleisher LA, et al. 2017 AHA/ACC focused update of the 2014 AHA/ACC guideline for the management of patients with valvular heart disease: a report of the American College of Cardiology/American Heart Association Task Force on Clinical Practice Guidelines. J Am Coll Cardiol. 2017;70:252-89. 
2. Lazam S, Vanoverschelde JL, Tribouilloy C, Grigioni F, Suri RM, Avierinos JF, et al; MIDA (Mitral Regurgitation International Database) Investigators. Twenty-year outcome after mitral repair versus replacement for severe degenerative mitral regurgitation: analysis of a large, prospective, multicenter, international registry. Circulation. 2017; 135:410-22.

3. Chikwe J, Toyoda N, Anyanwu AC, Itagaki S, Egorova NN, Boateng P, et al. Relation of mitral valve surgery volume to repair rate, durability, and survival. J Am Coll Cardiol. 2017;69:2397-406.

4. Nielsen SL, Nygaard H, Mandrup L, Fontaine AA, Hasenkam JM, He S, et al. Mechanism of incomplete mitral leaflet coaptation-interaction of chordal restraint and changes in mitral leaflet coaptation geometry. Insight from in vitro validation of the premise of force equilibrium. J Biomech Eng. 2002;124:596-608.
5. Anyanwu AC, Adams DH. The intraoperative "ink test": a novel assessment tool in mitral valve repair. J Thorac Cardiovasc Surg. 2007;133: 1635-6.

6. Serri K, Bouchard D, Demers P, Coutu M, Pellerin M, Carrier M, et al. Is a good perioperative echocardiographic result predictive of durability in ischemic mitral valve repair? J Thorac Cardiovasc Surg. 2006;131:565-73.e2.

7. Flameng W, Herijgers P, Bogaerts K. Recurrence of mitral valve regurgitation after mitral valve repair in degenerative valve disease. Circulation. 2003;107: 1609-13.

8. Grinberg D, Bruhat A, Cottinet PJ, Le MQ, Adams DH, Costa A. Mitral valve repair based on physical characterization of coaptation forces. J Thorac Cardiovasc Surg. 2020;159:e181-3. 